\title{
Food cue exposure and body image satisfaction: the moderating role of $\mathrm{BMI}$ and dietary restraint
}

Citation for published version (APA):

Fett, A. J., Lattimore, P., Roefs, A. J., Geschwind, N., \& Jansen, A. T. M. (2009). Food cue exposure and body image satisfaction: the moderating role of $\mathrm{BMI}$ and dietary restraint. Body Image, 6, 14-18. https://doi.org/10.1016/j.bodyim.2008.08.005

Document status and date:

Published: 01/01/2009

DOI:

10.1016/j.bodyim.2008.08.005

Document Version:

Publisher's PDF, also known as Version of record

Document license:

Taverne

Please check the document version of this publication:

- A submitted manuscript is the version of the article upon submission and before peer-review. There can be important differences between the submitted version and the official published version of record.

People interested in the research are advised to contact the author for the final version of the publication, or visit the DOI to the publisher's website.

- The final author version and the galley proof are versions of the publication after peer review.

- The final published version features the final layout of the paper including the volume, issue and page numbers.

Link to publication

\footnotetext{
General rights rights.

- You may freely distribute the URL identifying the publication in the public portal. please follow below link for the End User Agreement:

www.umlib.nl/taverne-license

Take down policy

If you believe that this document breaches copyright please contact us at:

repository@maastrichtuniversity.nl

providing details and we will investigate your claim.
}

Copyright and moral rights for the publications made accessible in the public portal are retained by the authors and/or other copyright owners and it is a condition of accessing publications that users recognise and abide by the legal requirements associated with these

- Users may download and print one copy of any publication from the public portal for the purpose of private study or research.

- You may not further distribute the material or use it for any profit-making activity or commercial gain

If the publication is distributed under the terms of Article $25 \mathrm{fa}$ of the Dutch Copyright Act, indicated by the "Taverne" license above, 


\title{
Food cue exposure and body image satisfaction: The moderating role of BMI and dietary restraint
}

\author{
Anne-Kathrin Fett ${ }^{\mathrm{a}, *}$, Paul Lattimore ${ }^{\mathrm{b}}$, Anne Roefs ${ }^{\mathrm{c}}$, Nicole Geschwind ${ }^{\mathrm{a}}$, Anita Jansen ${ }^{\mathrm{c}}$ \\ ${ }^{a}$ Department of Psychiatry and Neuropsychology, South Limburg Mental Health and Teaching Network, EURON, Maastricht University, P.O. Box 616, 6200 MD, \\ Maastricht, The Netherlands \\ ${ }^{\mathrm{b}}$ School of Psychology, Liverpool John Moores University, Liverpool, UK \\ ${ }^{\mathrm{c}}$ Department of Clinical Psychological Science, Maastricht University, Maastricht, The Netherlands
}

\section{A R T I C L E I N F O}

\section{Article history:}

Received 16 April 2008

Received in revised form 28 August 2008

Accepted 28 August 2008

\section{Keywords:}

Body image satisfaction

Body mass index

Restraint

Food cues

Exposure

\begin{abstract}
A B S T R A C T
Effects of cue exposure to high and low-caloric food on body image satisfaction and the moderating role of body mass index (BMI) and restraint were investigated in 77 lean unrestrained, lean restrained and overweight restrained females. Body (BS) and weight satisfaction (WS) were assessed before and after the cue exposure. Lean restrained participants were significantly less satisfied with their weight after cue exposure to high-caloric foods in comparison to cue exposure to low-caloric foods, whereas no such effect was present in overweight restrained and lean unrestrained participants. Low-caloric food cues did not influence WS. Food cues had a nonsignificant trend effect on BS. Yet, only lean unrestrained participants experienced significantly more BS in response to food cue exposure.
\end{abstract}

(c) 2008 Elsevier Ltd. All rights reserved.

\section{Introduction}

Body image satisfaction is often conceptualized as a discrepancy between current and ideal body shape (Garner, Garfinkel, \& O'Shauhnessy, 1985), or the degree of negative feelings about body shape, body parts and weight (Cash, Fleming, Alindogan, Steadman, \& Whitehead, 2002). Dissatisfaction with body image is regarded as a risk and maintenance factor in eating pathologies, such as obesity, binge eating, anorexia and bulimia nervosa (Edman, Yeates, Aruguete, \& DeBored, 2005; Stice \& Shaw, 2002) and appears to be associated with attempts to restrain ones food intake. Restrained eaters have the intention of controlling their weight, but often fail and indulge in high-fat palatable foods that they normally do not allow themselves to eat (Herman \& Polivy, 1980). According to cognitive behavioral models, low body image satisfaction reinforces dieting; this in turn is thought to foster the development of eating pathology (Stice \& Shaw, 2002). Research revealed that body image satisfaction fluctuates (Melnyk, Cash, \& Janda, 2004) and changes with context, especially in persons who are concerned about weight and shape (Tiggemann, 2001).

\footnotetext{
* Corresponding author at: Maastricht University, Department of Psychiatry and Neuropsychology (Vijverdal), Faculty of Health, Medicine and Lifesciences, P.O. Box 616, 6200 MD, Maastricht, The Netherlands.

E-mail address: A.Fett@sp.unimaas.nl (A.-K. Fett).
}

An important factor that causes fluctuations in body image satisfaction is food intake (Gardner, Espinoza, Urrutia, Morrell, \& Gallegos, 1990; Lattimore, 2005; Lattimore et al., 2008; Vocks, Legenbauer, \& Heil, 2007; Wardle \& Foley, 1989). A possible explanation for this phenomenon is that a person's expectations of the consequences of eating (e.g., weight gain) elicit these changes (Bruch, 1973). Apart from one study (Pietrowsky, Straub, \& Hachl, 2003), research shows that the consumption of food causes the desire to be thinner or reduced shape and weight satisfaction. This effect was found to vary with restraint and body mass index (BMI; $\mathrm{kg} / \mathrm{m}^{2}$ ). Vocks et al. (2007) showed that consumption of a highcaloric milkshake induced a decrease in body image satisfaction and that this reduction was positively correlated to restraint and worries about weight and shape. Wardle and Foley (1989) in contrast reported that food intake decreases body image satisfaction in unrestrained eaters, compared to restrained eaters (Wardle \& Foley, 1989). Other studies, additionally, implicated BMI as a moderator of this effect (Gardner et al., 1990; Lattimore, 2005). Lattimore (2005) found that BMI, but not restraint, moderated the relation between food intake and body shape satisfaction. Lean participants rated their current body size larger and showed a larger discrepancy between current and ideal size when satiated than when hungry. Overweight participants were unaffected by the manipulation. Gardner et al. (1990) studied the effects of satiety and hunger in lean and overweight participants. Lean participants' body size ratings were little affected by food intake. Overweight participants in turn estimated their body size larger 
after having eaten. As findings are equivocal, it remains uncertain how exactly food induced changes in body image satisfaction are moderated by BMI and restraint.

Importantly, previous research often required participants to consume high-caloric food in full awareness of its calorific content (Lattimore et al., 2008). Hence, changes in body image satisfaction could be due to cognitions about the expected effects of food intake instead of the direct effects of eating. Regarding that possibility, Lattimore et al. (2008) suggested that food cue availability might play a role in triggering food related changes in body image satisfaction. They found that when visual cues of a high-caloric meal were available, eating led to a reduction in body image satisfaction in overweight, compared to lean females. When visual food cues were removed, eating a high-caloric meal resulted in reduced body image satisfaction in lean females, whereas overweight females tended to show an improved body image. So, the findings of food intake studies could be attributed to both; the expectations about the effects of food intake, or to the direct, physical effects of the food (e.g., ingestion, fullness, or stomach ache). A recent study, which was conducted to elucidate this interpretative problem of food intake studies has shown that high-caloric food cues alone bring about decreases in weight satisfaction and that this effect is more pronounced in individuals with higher dietary restraint (Geschwind, Roefs, Jansen, Lattimore, \& Fett, 2008). However, how the effect of food cues is influenced by BMI has not been investigated.

The current study aimed to provide a more comprehensive test of whether cognitive effects of food cues can cause changes in body image satisfaction. We used a food cue exposure paradigm where individuals were not allowed to eat during the experimental procedure. To investigate how BMI and dietary restraint moderate the effects of food cues on body image satisfaction we examined lean $(\mathrm{BMI}<25)$ unrestrained, lean restrained, and overweight $(\mathrm{BMI}>25)$ restrained females. We expected that high-caloric food cues would cause decreased body image satisfaction in restrained individuals and that this effect would be more pronounced in those with a high BMI.

\section{Method}

\section{Participants}

To pre-select potential participants with a sufficient range of restraint scores a screening questionnaire was emailed to all female students of Liverpool John Moores University. Inclusion criteria were an age between 18 and 40 years, BMI $\geq 18<40$, no food allergies, no history of eating disorder or mental health problems, pregnancy, diabetes or using anti-depressant and/or weight loss medication. Seventy-seven female participants were included. A payment of $£ 10$ was given for participation. Participant characteristics are presented in Table 1.

\section{Design}

The effects of food cue exposure on body image satisfaction were assessed in a 2 (Exposure: high-caloric vs. low-caloric cues) $\times 3$ (Group: lean unrestrained (LUR) vs. lean restrained (LR) vs. overweight restrained (OWR)) between-subjects design. The primary dependent variables were change scores (post- minus pre-exposure) in body and weight satisfaction (BS and WS, respectively).

\section{Measures}

An eligibility questionnaire was used to select participants. The time between screening and the experiment was at least 2 weeks. We adapted the questionnaire from a Dutch questionnaire, which has been used previously to screen student populations for dietary restraint and BMI. The questionnaire contained three questions from Herman and Polivy's Restraint Scale (1980) and has proven to be a good indicator of the overall restraint status. To get estimations of BMI the questionnaire contained questions asking for height and weight. Additional questions checked the inclusion criteria. The questions for restraint, BMI and the inclusion criteria were disguised among irrelevant questions to keep the purpose of the study concealed.

The original Restraint Scale is a 10 -item scale that assesses the extent of intended restraint over food intake. It has excellent testretest reliability $(r=.95$; Allison, 1992) and a good internal consistency $(\alpha=.88)$. Restraint, as defined by the Restraint Scale is regarded as a trait like, stable construct (Polivy, Herman, \& Howard, 1988). Though it is considered a trait-measure, we chose to have the Restraint Scale completed 1 week after the experiment to prevent possible carry-over effects of cue exposure.

Visual analogue scales (VAS, $0-100 \mathrm{~mm}$, paper and pencil) are sensitive to subtle changes in emotion and cognition and have been proven to be reliable and valid under controlled conditions (De Boer et al., 2004; Stubbs et al., 2000). We used VAS to assess changes in body image satisfaction from pre- to post-exposure. Body image satisfaction was operationalized by two VAS on weight satisfaction (WS, "Right now, I feel not at all (0)/very (100) satisfied with my weight") and body satisfaction (BS, "Right now, I feel: not at all (0)/very (100) satisfied with my body"). The VAS were presented in a booklet that included irrelevant items to prevent participants from becoming aware of the true purpose of the study and to prevent possible memory effects from pre- to post-test.

\section{Procedure}

Prior to the study ethical approval was obtained from the University Ethics Committee. Based on the screening questionnaire participants were allocated to one of three groups (LUR, LR and

Table 1

Means and standard deviations for participant characteristics and measures of body and weight satisfaction by group and condition.

\begin{tabular}{|c|c|c|c|c|c|c|c|c|c|c|c|c|}
\hline \multirow[t]{3}{*}{ Variable } & \multicolumn{4}{|c|}{ Lean unrestrained } & \multicolumn{4}{|c|}{ Lean restrained } & \multicolumn{4}{|c|}{ Overweight restrained } \\
\hline & \multicolumn{2}{|c|}{ Low-cal $(n=13)$} & \multicolumn{2}{|c|}{ High-cal $(n=13)$} & \multicolumn{2}{|c|}{ Low-cal $(n=14)$} & \multicolumn{2}{|c|}{ High-cal $(n=12)$} & \multicolumn{2}{|c|}{ Low-cal $(n=12)$} & \multicolumn{2}{|c|}{ High-cal $(n=13)$} \\
\hline & $M$ & $S D$ & $M$ & $S D$ & $M$ & $S D$ & $M$ & $S D$ & $M$ & $S D$ & $M$ & $S D$ \\
\hline Age & 21.6 & 2.8 & 20.8 & 2.2 & 22.5 & 3.4 & 20.3 & 2.0 & 22.7 & 5.5 & 23.5 & 6.5 \\
\hline BMI & 19.9 & 1.5 & 21.1 & 1.8 & 21.8 & 1.5 & 22.0 & 1.4 & 31.3 & 3.6 & 29.0 & 2.7 \\
\hline Pre-BS & 65.7 & 23.6 & 57.1 & 20.7 & 41.3 & 15.3 & 40.7 & 20.1 & 26.5 & 21.2 & 23.0 & 11.6 \\
\hline Pre-WS & 73.6 & 19.3 & 56.5 & 23.8 & 38.7 & 16.6 & 36.1 & 16.6 & 21.8 & 18.0 & 21.3 & 10.8 \\
\hline Restraint & 8.1 & 3.5 & 7.9 & 4.0 & 17.7 & 3.8 & 17.4 & 3.0 & 20.2 & 3.5 & 20.9 & 4.6 \\
\hline$\Delta \mathrm{BS}$ & 5.8 & 6.9 & 6.5 & 7.2 & 0.1 & 10.4 & -1.0 & 9.7 & -1.3 & 14.8 & 5.0 & 12.9 \\
\hline$\Delta \mathrm{WS}$ & 3.0 & 5.5 & 6.1 & 10.5 & 1.7 & 7.4 & -5.0 & 7.1 & 0.7 & 6.7 & 5.1 & 11.0 \\
\hline
\end{tabular}

Note: $\Delta$ = change score (post-minus pre-test rating). 
OWR) according to BMI and restraint. The grouping was verified by measurements of BMI and restraint that were taken after the experiment. Participants switched groups when indicated by these post-experiment measurements. Individuals with a BMI below 25 were grouped as lean. Previous research has shown that the median score on the Restraint Scale is 13 in the UK (Wardle, 1986) and 11 in the Netherlands (Jansen, Louwerse, Leemans, \& Schouten, 1998), which is much lower than in the US (15 or 16). The median score in our British sample was perfectly in accordance with this prior research $(M d n=13.5)$, and therefore we based our division into low and high restrained eaters on this median score. Participants with score of 13 or lower were classified as unrestrained eaters, participants with a score of 14 or higher as restrained eaters.

Participants were randomly allocated to either the high or lowcaloric cue condition. They were either tested between 11 am and $1 \mathrm{pm}$ or between $3 \mathrm{pm}$ and $5 \mathrm{pm}$, as they had to refrain from eating and drinking (except water) for $2 \mathrm{~h}$ prior to the experiment. Participants were instructed that their last meal prior to abstinence had to be a sandwich and their compliance was checked on arrival.

Testing was done individually. First, the pre-exposure VAS was completed. The participant was informed that she participated in a study about the effects of mindfulness exercises on mental rest and well being during which she had to concentrate on different foods. To increase food related expectations, the participant was told that there would be a taste test at the end of the experiment and that she could eat as much as she wanted afterwards.

The participant was exposed to $25 \mathrm{~g}$ of cucumber, carrot and pepper in the low-caloric condition, or to chocolate, crisps and chocolate brownies in the high-caloric condition. Food items were presented separately for two minutes each (total exposure time $6 \mathrm{~min}$ ). To ensure that the participant really engaged with the food, an experimenter modelled the procedure. She instructed the participant to take a piece of food and to closely look at it, to smell it and to finally lick it. The participant was asked to concentrate and focus on her sensations, thoughts and feelings elicited by the food. After the exposure, the participant completed the post-exposure VAS. Finally, her height and weight was measured. Participants completed the Restraint Scale 1 week after the experiment $(M=6.71$ days, $S D=4.87)$. After testing was finished, they were debriefed by e-mail.

\section{Data analysis}

We conducted our analyses of variance with group (LUR vs. LR vs. OWR) and condition (low-caloric vs. high-caloric food) as independent and change in BS and WS as dependent variables. Where appropriate post hoc tests with Bonferroni correction were employed to explore simple effects.

\section{Results}

The relevant means and standard deviations per group and condition are displayed in Table 1.

\section{Participant characteristics}

The groups differed significantly in restraint, $F(2,71)=78.39$, $p<.01$, and pre-exposure scores of WS, $F(2,71)=38.61, p<.01$, and BS, $F(2,71)=23.54, p<.01$. Pair-wise comparisons showed that OWRs scored highest on restraint and lowest on WS and BS, followed by LRs and LURs, with all group differences being significant, all $p<.05$. The groups differed significantly in BMI, $F(2$, $71)=138.79, p<.01$. Post hoc tests showed that OWRs had higher BMIs than LRs and LURs, both $p<.01$. There was no difference between the lean groups, $p>$.1. A significant group $\mathrm{x}$ condition interaction qualified the main effect of group, $F(2,71)=3.86$, $p<.05$. Yet, post hoc tests per cue condition revealed that in both conditions OWRs had higher BMIs than LRs and LURs, all $p<.05$, and that there were no differences between the lean groups, both $p>.16$. The groups did not differ significantly in age, $F(2$, 71) $=1.66, p=.19$.

\section{Change in body satisfaction}

There was a nonsignificant trend effect of group, $F(2,71)=2.56$, $p=.08$. LURs $(M=6.2, S D=6.9)$ and OWRs $(M=1.9, S D=13.0)$ had positive change scores. LRs $(M=-0.4, S D=9.9)$ had a negative change score. One-sample $t$-tests showed that the change scores did not differ significantly from zero for OWRs and LRs, both $p=1$, but that they did for LURs, $t(25)=4.54, p<.01$. There was no significant effect of condition, $F(1,71)=.67, p=.42$, and no significant interaction, $F(2,71)=.84, p=.44$. Food cue exposure had little impact on BS, and high-caloric cues did not lead to more pronounced changes in BS than low-caloric cues.

\section{Change in weight satisfaction}

A significant main effect of group was revealed, $F(2,71)=3.86$, $p<.05$. Change scores were positive for LURs $(M=4.54, S D=8.39)$ and OWRs $(M=3.0, S D=9.26)$ and negative for LRs $(M=-1.42$, $S D=7.9$ ). One-sample $t$-tests showed that the change scores did not differ significantly from zero for OWRs and LRs, both $p>.36$, but that they did for LURs, $t(25)=2.75, p<.05$. There was no main effect of condition, $F(1,71)=.03, p=.87$. A significant group $\times$ condition interaction qualified the main effect of group, $F(2$, $71)=3.41, p<.05$. Analysis of variance per condition indicated no group differences in the low-caloric condition, $F(2,36)=.39, p=1$, but did in the high-caloric condition, $F(2,35)=4.90, p<.05$. Specifically, multiple comparisons in the high-caloric condition indicated significant differences between LRs and LURs, $p<.05$, and between LRs and OWRs, $p<.05$. No significant difference was present between LURs and OWRs, $p=1$. Looking at the effect of exposure condition per group, we found no differential effect of condition for LURs, $F(1,24)=.87, p=1$, and OWRs, $F(1,23)=1.49$, $p=.69$, but we did for LRs, $F(1,24)=5.38, p<.05$. A one-sample $t$ test for LRs change scores per condition showed that the WS change was significant in the high-caloric condition, $t(11)=-2.44$, $p<.05$, but not in the low-caloric condition, $t(13)=.83, p=.42$ (for means and standard deviations see Table 1$)$.

\section{Discussion}

Food cue exposure is believed to evoke fear of weight gain or overeating in those who are concerned about their weight and shape. We therefore assumed that especially high-caloric food cues would lead to decreased body image satisfaction in restrained individuals and that these effects would be more pronounced with increasing BMI.

Regarding WS changes, averaged over the two conditions (i.e., high-caloric and low-caloric cue exposure), it appeared that food cues had a positive influence on LURs. After investigating the interaction, as expected, only the high-caloric condition had a differential effect on our groups. LRs experienced a negative change in WS. This is in line with the idea that high-caloric food elicits negative food related expectations and subsequent decreases in WS in those who are restrained. Unexpectedly, the WS of OWRs was not affected by the cue exposure, and no differences were found between high-caloric and low-caloric food cues. For the LURs, the positive effect of food-cue exposure was 
independent of the type of food. Apparently, high-caloric food cues are associated with negative food related expectations in a lean sub-group of restrained individuals.

Our expectations were not supported for BS changes. We found a nonsignificant trend effect of group. Cue type had no effect at all. Again, the BS change from pre- to post-exposure was significant for LURs, indicating that they experienced more BS in response to food cues in general. The different reactions in terms of BS and WS support our approach to measure body image satisfaction with both weight and shape related measures. As previously proposed by Geschwind et al. (2008) this finding may indicate that weight satisfaction is closer and more explicitly coupled to caloric information than body satisfaction.

Overall, LRs appear to experience reduced WS after exposure to high-caloric cues, whereas LURs showed an increase in both WS and BS after food cue exposure (i.e., no differential effect of high vs. low-caloric food cues). Food cues did not affect OWRs body image satisfaction. Lattimore et al. (2008) suggested that reduced body image satisfaction in overweight/restrained individuals after food intake might be due to their heightened responsiveness to food cues. We also assumed that OWRs would be even more likely to perceive food cues as a threat to their control of eating and of weight gain than LRs. Our finding that LR participants experience decreased WS in response to high-caloric food meets the hypothesis about the effects of restraint. This is in line with the schema theory of body dissatisfaction, according to which activation of body and weight self-schemata will reduce body satisfaction in people who perceive the body-weight domain as self-defining (Corte \& Stein, 2005). In correspondence with the findings of Geschwind et al. (2008) our study shows that in particular for LRs actual eating is not necessary for decreased body image satisfaction to occur. Specifically, these effects may be grounded in thought-shape fusion, a cognitive distortion comprised of beliefs that thinking about eating high-caloric or forbidden food results in weight gain, is morally wrong and increases feelings of fatness. In line with our results a recent study showed that thought-shape fusion induced by food related cognitions does increase feelings of fatness and that his effect is larger in restrained than unrestrained individuals (Coelho, Carter, McFarlane, \& Polivy, 2008). Finding no change in OWRs body image satisfaction after exposure to high-caloric food suggests a different underlying mechanism. In this overweight group the mere exposure to high-caloric cues may not elicit negative cognitions related to the effects of food intake. Food cues appear to be associated with certain feelings, states or situations. Food can therefore cue negative post-consumption consequences, as weight gain. Yet, it also has rewarding properties and reduces hunger and unpleasant accompanying bodily feelings. Hence, it could be that OWRs and LURs had more neutral or positive associations with food, especially after fasting longer than $2 \mathrm{~h}$. Besides, in OWRs negative food related expectations may only become activated after actual food consumption (e.g., due to feelings of guilt because of broken diet rules). Another possible explanation of the absent changes in OWRs might be a floor effect in which body image satisfaction does not decrease further.

To date little research has investigated the effects of food cues on body image satisfaction (Carter, Bulik, Lawson, Sullivan, \& Wilson, 1996; Geschwind et al., 2008). With our study we aimed to disentangle the moderating effects of BMI and restraint on body image satisfaction. Our findings add novel information showing that the effects of food cues depend on an interaction of dietary restraint and BMI. Future research is needed to further investigate the phenomenon of cue induced changes in body image satisfaction. Understanding more about the operating mechanisms would be very valuable in a society that continuously becomes "bigger" and that constantly is exposed to overwhelming amounts of food cues. Knowing more about the effects of food cue exposure may also be very valuable for the development of treatment approaches and theory in the clinical field, where food cue exposure is already commonly used in the treatment of bulimia nervosa. Our study had several limitations that should be taken into account by future research. To increase the experimental effects the exposure paradigm should be made more threatening (e.g., present more food for a longer duration) and closer to real world food exposure. In addition, due to the use of self-report measures our results may have been influenced by biases and matters of self-presentation. Upcoming research should strive to employ other, more objective measures that are less susceptible to these problems (autonomic measures, reaction time) and which therefore could prove valuable in tracking food cue related changes in body image.

\section{Acknowledgements}

This report was presented at the British Feeding \& Drinking Group Annual Meeting hosted by Northumbria University, UK. The project was partly funded by an award to Lattimore, Roefs and Jansen from the British Academy for the Humanities and the Social Sciences grant No.: LRG-4152.

\section{References}

Allison, D. B. (1992). A comparison of the psychometric properties of three measures of dietary restraint. Psychological Assessment, 4, 391-398.

Bruch, H. (1973). Eating Disorders: Obesity, anorexia nervosa and the person within. London: Routledge and Kegan.

Carter, F. A., Bulik, C. M., Lawson, R. H., Sullivan, P. F., \& Wilson, J. S. (1996). Effect of mood and food cues on body image in women with bulimia and controls. International Journal of Eating Disorders, 20, 65-76.

Cash, T. F., Fleming, E. C., Alindogan, J., Steadman, L., \& Whitehead, A. (2002). Beyond body image as a trait: The development and validation of the Body Image States Scale. Eating. Eating Disorders, 10, 103-113.

Coelho, J. S., Carter, J. C., McFarlane, T., \& Polivy, J. (2008). Just looking at food makes me gain weight: Experimental induction of thought-shape fusion in eating-disordered and non-eating-disordered women. Behaviour Research and Therapy, 46, 219-228.

Corte, C., \& Stein, K. F. (2005). Body-weight self-schema: Determinant of mood and behavior in women with an eating disorder. Journal of Applied Social Psychology, 35, $1698-1718$

De Boer, A. G. E. M. , Van Lanschot, J. J. B., Stalmeier, P. F. M., Van Sandick, J. W., Hulscher, J. B. F., \& De Haes, J. C. J. M. (2004). Is a single-item visual analogue scale as valid, reliable and responsive as multi-item scales in measuring quality of life? Quality of Life Research, 13, 311-320.

Edman, J. L., Yeates, A., Aruguete, M. S., \& DeBored, K. A. (2005). Negative emotion and disordered eating among obese college students. Eating Behaviors, 6, 308-317.

Gardner, R. M., Espinoza, T., Urrutia, R., Morrell, J., \& Gallegos, V. (1990). The effect of hunger on the obese: Feeling full, feeling fat. The Psychiatric Forum, 57-62.

Garner, D. M., Garfinkel, P. E., \& O'Shauhnessy, M. (1985). The validity of the distinction between bulimia with and without anorexia nervosa. American Journal of Psychiatry, 142, 581-587.

Geschwind, N., Roefs, A., Jansen, A., Lattimore, P., \& Fett, A. (2008). Dietary restraint modulates the effects of food cue exposure on women's body and weight satisfaction. Appetite, 51, 735-738.

Herman, C. P., \& Polivy, J. (1980). Restrained eating. In A. Stunkard (Ed.), Obesity (pp. 208-225). Philadelphia: Saunders.

Jansen, A., Louwerse, E., Leemans, N., \& Schouten, E. (1998). Self-esteem as a better predictor of restrained eaters' food intake than attributional style and disinhibition tendency. European Journal of Personality, 12, 43-56.

Lattimore, P. (2005). Body dissatisfaction in females varies according to deprivation state and is modified by weight rather than restraint status. Appetite, 45, 356-359.

Lattimore, P., Roefs, A., Jansen, A., Lau, A., Fett, A., \& Geschwind, N. (2008). High-caloric food affects body and weight dissatisfaction in females as a function of food cue availability and body mass index, Unpublished manuscript.

Melnyk, S. E., Cash, T. F., \& Janda, L. H. (2004). Body image ups and downs: Prediction of intra-individual level and variability of women's daily body image experiences. Body Image, 1, 225-235.

Pietrowsky, R., Straub, K., \& Hachl, P. (2003). Body dissatisfaction in female restrained eaters depends on food deprivation. Appetite, 40, 285-290.

Polivy, J., Herman, C. P., \& Howard, K. I. (1988). The Restraint Scale: Assessment of dieting. In M. Hersen \& A. S. Bellack (Eds.), Dictionary of behavioral assessment techniques (pp. 377-380). New York: Pergamon Press.

Stice, E., \& Shaw, H. E. (2002). Role of body dissatisfaction in the onset and maintenance of eating pathology a synthesis of research findings. Journal of Psychosomatic Research, 53, 985-993. 
Stubbs, R. J., Hughes, D. A., Johnstone, A. M., Rowley, E., Reid, C., Elia, M., et al. (2000). The use of visual analogue scales to assess motivation to eat in human subjects: A review of their reliability and validity with an evaluation of new hand-held computerized systems for temporal tracking of appetite ratings. British Journal of Nutrition, 84, 405-415.

Tiggemann, M. (2001). Person $\times$ situation interactions in body dissatisfaction. International Journal of Eating Disorders, 29, 65-70.
Vocks, S., Legenbauer, T., \& Heil, A. (2007). Food intake affects state body image: Impact of restrained eating patterns and concerns about eating, weight and shape. Appetite, 49, 467-475.

Wardle, J. (1986). The assessment of restrained eating. Behaviour Research and Therapy, 24, 213-215.

Wardle, J., \& Foley, E. (1989). Body image: Stability and sensitivity of body satisfaction and body size estimation. International Journal of Eating Disorders, 8, 55-62. 